\title{
JOAN MERCADER: LA INTERVENCIÓ DEL BATLLE GENERAL DEL REGNE DE VALÈNCIA EN LA POLÍTICA GRANADINA D'ALFONS EL MAGNÀNIM' ${ }^{1}$
}

\author{
Roser SALICRÚ I LLUCH \\ Institució Milà i Fontanals \\ CSIC - Barcelona
}

\section{JOAN MERCADER, «PRECURSOR DE LA DIAFANITAT RENAIXENTISTA»}

En el seu documentat Estudio documental sobre el bayle general del reino de Valencia, su autoridad y jurisdicción ${ }^{2}$, que abasta, des de 1404 fins a 1451, tota la primera meitat del segle XV, Leopoldo Piles ja destacava el paper que podia tenir el batlle general del regne de València tant en relació amb les que ell denominava autoritats estrangeres com en qualitat de conseller reial ${ }^{3}$. Però, amb una orientació eminentment jurídica, institucional i orgànica, defugia, volgudament i encertadament, d'acord amb els objectius de la seva anàlisi, la caiguda en personalismes.

Tanmateix, és probablement quan busquem aquest personalisme quan, justament, la influència del batlle en els dos aspectes assenyalats, la política internacional de la Corona i l'assessorament de la monarquia, pot apreciar-se amb més força.

Al llarg bona part del període estudiat per Piles, el batlle general del regne de València fou el jurista valencià Joan Mercader, qui, nomenat el 7 d'octubre de 1412

1 Abreviatures utilitzades: $A C A=$ Arxiu de la Corona d'Aragó; $A E M=$ Anuario de Estudios Medievales; $A H A M=$ Acta Historica et Archaeologica Mediaevalia; ARV = Arxiu del Regne de València; BRABLB = Boletín de la Real Academia de Buenas Letras de Barcelona; C. = Cancelleria; CEM = Cuadernos de Estudios Medievales; $\mathrm{CR}=$ Cartes Reials; reg. = registre; $f$., ff. = foli, folis; $\mathrm{MEAH}=$ Miscelánea de Estudios Árabes y Hebraicos; $M R=$ Mestre Racional; $r=$ recto; $v=$ verso.

2 València, Institución Alfonso el Magnánimo-CSIC, 1970.

3 Cf. op. cit., p. 112. 
per Ferran d'Antequera, substituí en el càrrec a Nicolau Pujades ${ }^{4}$ i el detingué, fins que fou succeït pel seu fill primogènit, Berenguer, durant més de dues dècades. Joan Mercader fou, per tant, batlle general del regne de València al llarg de tot el regnat de Ferran I i durant bona part del del seu fill, Alfons el Magnànim.

No fou pas perquè sí que algunes de les cartes conservades a l'Arxiu de la Corona d'Aragó que aquest personatge adreçà a Ferran d'Antequera mereixeren un estudi monogràfic de Margarida Tintó ${ }^{5}$ que ja en ressaltà l'escriptura incisiva i dura, punyent i directa; o que, en comentar-ne una en el seu estudi sobre sant Vicent Ferrer i la casa reial d'Aragó, Martínez Ferrando en qualificava l'estil epistolar com a "precursor de la diafanitat renaixentista» ${ }^{6}$. Perquè, tant en el seu paper com a conseller de Ferran I com, després, en el de conseller d'Alfons el Magnànim, tot i que gairebé sempre guardà fidelitat i acatà les ordres de la Corona, Mercader, home d'idees clares i segures, no s'estigué pas mai de manifestar, amb convicció, les seves pròpies opinions i les seves discrepàncies, portant la contrària, si calia, als monarques, amb arguments tan enraonats i justificacions tan concloents i persuasives que, almenys en el cas del Magnànim, sovint li feren mutar, de soca-rel, no només decisions ja preses sinó també actituds i parers que, abans de rebre l'assessorament del batlle, apareixen fermament i profundament assentats.

La ploma de Joan Mercader, a través d'una particular prosa epistolar -si és que podem anomenar-la així- que defuig tot l'encotillament i monotonia repetitiva propis, en teoria, d'un estil cancelleresc que, ocasionalment, és capaç oferir-nos tasts de l'estil dels de Mercader, pot considerar-se, de ben segur, com un els testimoniatges més aguts, loquaços i brillants per descriure alguns dels aspectes de la València del quatrecents.

Del regnat de Ferran I, Margarida Tintó ja en va recollir, per exemple, algunes de les diatribes en contra d'un focus de corsaris o de pirates castellans que es refugiaven al port de Cartagena i que tenien com a blanc les embarcacions valencianes que comerciaven amb «terra de moros»; o, més pròpiament, en contra de la passivitat del monarca en un moment en el qual la Corona d'Aragó i Castella estaven vinculades per una mateixa treva (que no reconeixia la llibertat de comerç però que s'interpretava,

4 Cf. M. TINTÓ SALA, Cartas del baile general de Valencia, Joan Mercader, al rey Fernando de Antequera, València, Instituto Valenciano de Estudios Históricos-Institución Alfonso el Magnánimo, Diputación Provincial de Valencia, CSIC, 1979, p. 32 i docs. I i II de l'apèndix documental, pp. 275-277 (ACA, C., reg. 2396, t. 174r-v).

5 Vegeu la nota precedent.

6 J.E. MARTINEZ FERRANDO, F. SOLSONA CLIMENT, San Vicente Ferrer y la casa real de Aragón (Documentación conservada en el Archivo Real de Barcelona), Barcelona, CSIC-Biblioteca Balmes, 1955, p. 19. 
en aquest aspecte, de manera contraposada des d'uns i altre regnes) amb Granada i amb el sultanat benimerí de Fes? .

Fent-se ressò de la veu i de l'opinió de la classe mercantil valenciana, Mercader intentà convèncer el monarca de la licitud i importància d'aquest comerç fins i tot en el cas que en fossin objecte mercaderies prohibides. Segons ell, per al regne de València, aquest tràfic, que girava a l'entorn de l'intercanvi de fruites seques del regne per or africà, era cabdal, perquè en depenia l'afluència d'or a la seca de la ciutat ${ }^{8}$. Evidentment,

7 Sobre les treves amb Granada signades per Ferran d'Antequera, remeto als ja clàssics $M$. ARRIBAS PALAU, Las treguas entre Castilla y Granada firmadas por Fernando I de Aragón, Tetuan, Centro de Estudios Marroquíes-Editora Marroquí, 1956, I J. TORRES FONTES, La regencia de don Fernando el de Antequera y las relaciones castellano-granadinas (1407-1416), [IV] Las treguas, "MEAH" XXII (1973), pp. 7-59; però vegeu, igualment, els meus R. SALICRÚ I LLUCH, Posibilidades de reanudación de la guerra de Granada a finales del reinado de Fernando I de Aragón (1415-1416), dins La Península lbérica en la era de los descubrimientos (1391-1492). Actas III Jornadas Hispano-Portuguesas de Historia Medieval. Sevilla 25-30 de noviembre 1991, Sevilla, Junta de Andalucía-Universidad, 1997, vol. II, pp. 1437-1452; idem, El sultanat de Granada i la Corona d'Aragó, 1410-1458, Barcelona, Publicacions de P'Abadia de Montserrat - CSIC, 1998, pp. 67-117; idem, L'ambaixada a Fes d'Antoni Queixal i Ramon de Conesa (1413-1414), "AHAM»19 (1998), en premsa, i idem, La treva de 1418 amb Granada: la recuperació de la tradició catalanoaragonesa, "AEM» 27/2 (1997), en premsa.

8 «tot quant or entra en aquest regne ve a mà de les mercaderies qui van en terra de moros e porten-ne dobles, e com són açí meten-les en la seca, axí que.Is moros mercaders e los christians qui han compayies ab ells, porten de ací allà figues, pansses, garrofes e semblants coses, e porten-ne dobles de lla ací, perquè és molt neçessari al ben públich de aquest regne que.ls moros mercaders e llurs companyies sien mantenguts per vós [Ferran I]» (ACA, C., CR Ferran I, caixa 4, núm. 445. 1413, setembre, 29. València; ed. M. TINTÓ, Cartas del baile..., doc. 12, pp. 175-176 [el contingut de les caixes de les Cartes Reials de Ferran I ha estat modificat des del moment de la publicació de l'obra de Tintó, per això no es correspon amb el que apareix al seu estudi, però la numeració de les cartes és la mateixa; les citacions de cartes publicades les he reproduïdes tal com les transcriuen els seus editors]). Una de les cartes més interessants que publica Tintó fa referència, justament, als efectes que la pirateria dels castellans tenia sobre l'economia del regne, que el battle polaritzava a l'entorn de la fruita seca: «En aquest regne, per gràcia de Déu, ha molt bona cullita de figues e de panses, qui és un aver que d'açí a sis meses serà tot podrit. E si.s pot navegar segurament serà leugera cosa de entrar en aquest regne çinquanta milia dobles e pus. $E$ per nostres peccats, castellans ab naus et ab baleners se prenen totes les fustes e béns que poden atènyer de nostres vassalls; e per aquesta rahó los mercaders de aquest regne no gosen comprar gens de la dita figa e pansa e axí.s podrirà en aquest regne e les dobles se romandran en Barberia e los mesquins lauradors, qui hi han maltret de açò que.s deurien enrequir, los tornarà en pobrea e misèria» (ACA, C., CR Alfons IV, caixa 15, núm. 1789. 1414, setembre, 12. València; ed. M. TINTÓ, Cartas del baile..., doc. 66, pp. 232-233). Poc abans, a la primeria de gener del mateix any 1414, Mercader ja havia, també, avaluat en més de 50.000 dobles les mercaderies que els valencians tenien en "terra de moros", fet que considerava més que suficient perquè Ferran intentés acabar, d'una vegada, amb aquell «niu de pirates": "donets recapte al fet de Cartagènia e als altres ports de Castella, que vostres vassalls hi sien ben tractats. E provehits-hi tost, car vostres mercaders vassalls tenen al present en terra de moros, a seny dels qui o entenen, més de cinquanta milia dobles, e tots stan ab gran dupte, e yo ab ells, que de tornada no.u prenguen tot los cossaris qui són en les mars de Cartagènia» (ACA, C, CR Ferran I, caixa 8, núm. 758. 1414, gener, 4. València; ed. ibídem, doc. 22 bis, p. 187). Sobre el consum i comerç de fruita seca a la Baixa Edat Mitjana, remeto a M.T. FERRER I MALLOL, Figues, panses, fruita seca i torrons, dins La Mediterrània, àrea de convergència 
els sarraïns eren enemics de la fe, i calia combatre'ls i conquerir-los, però el batlle estava convençut que el tràfic amb terres musulmanes era, justament, allò que permetria obtenir l'or que, si plau a Jhesuchrist e a la Verge Maria, podria ser per Ferran gran socors en llur conquesta, mentre que, de les panses i de les figues, si no s'exportaven, aviat no podria fer-se'n res, perquè al cap d'un mes serien podrides. Per tant, al capdavall, segons el batlle, podia considerar-se que els valencians intercanviaven fems per dobles ${ }^{9} i$, en conseqüència, si hom prenia consciència d'aquest intercanvi tan particular, podia arribar-se fàcilment a la conclusió que no valia la pena atiar corsaris contra els mercaders que comerciaven amb Barbaria perquè, fins i tot, podia ser contraproduent ${ }^{10}$.

Tintó també va donar a conèixer, per exemple, una carta on el batlle es permetia qüestionar a Ferran d'Antequera que la via de vendes de lochs (...) com si fossen bous o moltons o altres coses semblants donades a comerçi fos la més adequada perquè la Corona pogués obtenir més ingressos, car, segons el seu parer, ço que ara.XXX. anys fon venut per $X$ milia sous, ha donat solament de emoluments al qui ho posseeix, deu milia florins, e vós e vostres antecessors han perdut los $X$ milia florins i, per Mercader, la sperança de quitar se val poch, car les necessitats tots temps foren e seran, e encara no és passada la una ja succeeix l'altra'1.

Però Tintó va recollir, només, el testimoniatge de les cartes de Joan Mercader a Ferran I. Aquestes cartes, sovint aconselladores, ja donen una mesura de la forta personalitat d'un personatge capaç de posar de manifest les seves opinions, sense circumloquis, per més que fossin completament contràries als designis del monarca. Però si Ferran d'Antequera es mantingué, normalment, ferm en els seus propòsits, durant el regnat d'Alfons el Magnànim, en canvi, al llarg del qual el batlle continuà etzibant les seves invectives, Mercader fou capaç, una vegada rere l'altra, de convèncer,

de sistemes alimentaris (segles V-XVIII). XIV Jornades d'Estudis Històrics i Locals, Palma de Mallorca, Institut d'Estudis Baleàrics, pp. 191-208.

9 «car ab les dobles de terra de moros vós, senyor, si plau a Jhesuchrist e a la Verge Maria, haurets gran socors en llur conquesta, e no.u haurets de la panssa e figa, qui d'açí a un mes serà tota podrida. $E$, com axí lo senyor rey de Castella se donàs a càrrech de consciència que vostres vassalls trasquen de fems dobles de terra de moros, no cal dar loch a cossaris contra vostres vassalls" (ACA, C., CR Ferran I, caixa 8, núm. 758. 1414, gener, 4. València; ed. M. TINTÓ, Cartas del baile..., doc. 22 bis, p. 187).

10 Per si això encara fos poc, i per evitar les reticències que el zel religiós del monarca podia oposar a la restitució d'una embarcació carregada de blat que es dirigia a Barbaria I que havia estat capturada a Cartagena, el batlle gosava demanar al monarca que no permetés que els castellans s'erigissin en confessors i en jutges espirituals dels valencians, car ja'ls lexats Jhesuchrist jutges e confessors, no ballaners ne galliotes, mas bons prelats e curats, cosa de la qual, segons sembla, fins i tot havia arribat a convèncer a fra Vicent Ferrer, amb qui havia parlat d'aquesta matèria (...) per mon descàrrech, i que es mostrava disposat a fer, també, amb el confessor reial (b'en parlaré volenter ab vostre confessor, ACA, C., CR Ferran I, caixa 8, núm. 25. 1414, març, 6. València, ed. J.E. MARTíNEZ, F. SOLSONA, San Vicente Ferrer..., doc. 38, pp. 67-68).

11 ACA, C., CR Ferran I, caixa 15, núm. 1830. 1414, novembre, 16. València. Ed. M. TINTÓ, Cartas..., doc. 75 . 
de fer canviar d'opinió o d'imposar la seva al nou monarca, que, per tant, ens apareix, almenys davant dels assenyats raonaments del batlle, molt més dúctil i mal.leable.

Ben poc després de la mort del seu pare, per exemple, a mitjan setembre de 1416, Joan Mercader ja es permetia negar-se a acceptar la creació de l'ofici de lloctinent de batlle del Grau de València i, menys encara, la persona designada per Alfons, al.legant, entre altres raons, que, despuix que aquest regne de València fou conquest (...) de poder de moros no n'hi havia pas mai hagut ni era necessari; que un lloctinent, en absència seva, hauria de regir com si fos ell mateix l'ofici i que, com que ell n'era quasi contínuament absent, el lloctinent del Grau esdevindria, en realitat, batlle general e yo seria, en aquesta ciutat, quasi una stàtua, ja que dels fets de aquest offici, dels cent los noranta se spatxen per la mar, que ell no podia pas fer-se responsable i retre comptes a Alfons d'una persona que no hagués nomenat ell mateix, perquè no era de la seva confiança; o que, amb la migradesa de les rendes reials de València (vostra reebuda és tant pocha que no.n viuria bé un baró) ${ }^{12}$, allò que calia era reduir i no pas augmentar oficis - cosa que assegurava que Ferran ja li havia encarregat que fes però que, a causa de la seva mort, havia quedat paralitzada-, ja que cascun jorn siem a vostra taula en nostres cases e menjam de la vostra bossa, en aquest regne, qui molt qui poch, de XXII batles ansús, e entre tots vós no.n reebets l'any mil florins, o sia que, a una gallina, deu menjadors ${ }^{13}$.

Però és, probablement, en l'àmbit de la política granadina on trobem els exemples que posen més de manifest -i reiteradament- la influència que Mercader va exercir sobre el Magnànim, o l'ascendent que aquest va deixar que tingués sobre ell.

\section{LA INTERVENCIÓ DE MERCADER EN LA POLÍTICA GRANADINA D'ALFONS EL MAGNÀNIM}

És evident que, tant per la proximitat geogràfica i el caràcter fronterer del regne de València -o, almenys, de la batllia del regne de València dellà Xixona- com pels contactes, no només politicodiplomàtics sinó també mercantils i humans, amb el sultanat nassarita, que tenien en la ciutat i regne de València un indubtable punt de referència ${ }^{14}$

12 A la primeria del segle XV, poden estimar-se a l'entorn d'uns 700.000 sous, o d'uns 63.600 florins (vegeu E. GUINOT, El patrimoni reial al País Valencià a inicis del segle XV, «AEM» 22 (1992), pp. 581-639, i en concret el quadre 31, p. 636), però hem de tenir en compte que aquestes dades no són pas les dels ingressos reals, sinó les de les rendes teòriques, perquè no n'hi ha deduïdes les dates $O$ assignacions fetes sobre elles.

13 ACA, C., CR Alfons IV, caixa 3, núm. 303. 1416, setembre, 12. València.

14 És suficient donar una ullada als capítols que L. PILES, Estudio..., pp. 27-61, dedica a l'autoritat del batlle sobre qüestions marítimes, sarraïns, captius, jueus $i$ comerç, 0 als estudis que la historiografia valenciana ha dedicat a aquests aspectes, per fer-se'n una idea. 
pel regne mateix però també per tota la Corona catalanoaragonesa ${ }^{15}$, tant el batlle general com el seu equivalent a la part més meridional del regne sempre havien tingut un paper destacat com a intermediaris en les relacions amb Granada, tot i que la Corona sempre havia conservat la preeminència ${ }^{16}$.

En el segle XV, en canvi, durant el regnat del Magnànim, assistim a una implicació cada cop més determinant $i$ directa del batlle en les relacions amb el sultanat.

Encara que Alfons el Magnànim s'allunyés de la Península i, també, de les qüestions peninsulars - que foren deixades, en bona part, en mans del seu germà Joan de Navarra i, ocasionalment, de la seva muller, la reina Maria-, el monarca va seguir, amatent, tot allò que succeïa a Granada. I si bé l'aparent estabilitat interna nassarita que s'estén des de 1432 fins a 1445 no possibilità ni féu necessàries preses de posició semblants a les que havia adoptat en els decennis anteriors, i tot i que les seves relacions amb Muhammad IX l'Esquerrà, que regnà durant aquesta etapa, continuaren essent mútuament cordials, la força de la distància física les féu, inevitablement, menys intenses i més espaiades i ocasionals. Fou, justament, des d'aleshores, quan assolí una major fermesa el paper de mediador i, gairebé, d'interlocutor directe amb el sultanat del batlle general del regne de València.

Berenguer Mercader, per exemple, el fill i substitut en el càrrec de Joan, o dos altres fills seus i, per tant, germans de Berenguer, Galceran i Perot, que actuaren com a lloctinents o regents seus, operaren amb prou independència, especialment de 1440 en endavant, i sobretot en moments de desmembració del sultanat, en allò que tocava al sector oriental nassarita (el principat o senyoria d'Almeria), mentre tingué Yusuf ibn Ahmad, Muhammad el Xic o Abu-l-Hasan Ali al capdavant ${ }^{17}$.

Però fou, sobretot, mentre el batlle fou Joan Mercader quan el seu poder decisori, ja no en allò que tocava les qüestions que podríem considerar més «regionals» sinó en el govern de la política granadina de la Corona a un nivell que podríem considerar interestatal, fou quasi absolut, encara que fos amb l'aquiescència reial. I, aleshores, no pas perquè Alfons es desentengués, de cap manera i ben al contrari, de les qüestions granadines, sinó perquè la seva forta personalitat i les seves idees clares tingueren un fort ascendent sobre el nou monarca, probablement més dubitatiu, influenciable i inexpert que no pas el seu pare Ferran.

Les mostres que testimonien de manera més significativa la influència que Mercader va tenir en la política granadina del Magnànim i en la mutació dels seus designis són, fonamentalment, quatre.

15 La capital valenciana era, per exemple, habitualment, el punt d'arribada i de partença dels ambaixadors nassarites, encara que, en haver d'anar a trobar els reis, la seva destinació fos una altra (vegeu-ho, per exemple, a M.T. FERRER I MALLOL, La frontera amb l'Islam en el segle XIV. Cristians i sarraïns al País Valencià, Barcelona, Institució Milà i Fontanals-CSIC, 1988, o a R. SALICRÚ, El sultanat...); i València també era, de manera general, el lloc de pas o d'establiment dels emigrants i dissidents nassarites (vegeu, en aquest sentit, idem, Caballeros granadinos emigrantes y fugitivos en la Corona de Aragón durante el reinado de Alfonso el Magnánimo, dins // Estudios de Frontera. Actividad y vida en la frontera, Jaén, Diputación Provincial, 1998, pp. 727-748).

16 Vegeu-ho, per exemple, a M.T. FERRER, La frontera...

17 Remeto, en aquest sentit, a R. SALICRÚ, El sultanat..., de la p. 369 en endavant. 
La primera, relacionada, com en el cas dels pirates de Cartagena durant el regnat de Ferran I, amb el comerç valencià amb «terra de moros», induí el Magnànim a un canvi d'actitud radical respecte al que les fonts de cancelleria i les municipals valencianes anomenen el "contracte de la seda" -o monopoli d'importació de la seda granadina que diversos mercaders valencians aconseguiren, el 1417, de Yusuf III de Granada-.

La segona i la tercera, fan referència a l'elaboració i negociació, de primer, i al fracàs, després, del tractat de 1418 amb Muhammad VIII el Petit de Granada -que és l'únic tractat amb el sultanat nassarita que s'ha conservat del regnat d'Alfons-, tractat que si acabà fracassant fou, en bona mesura, a causa, encara que sigui de manera indirecta, de la voluntat de Mercader de contrarestar o de neutralitzar els efectes del "contracte de la seda» que ell mateix havia intentat evitar, per altres mitjans, que acabés de cristal.litzar.

I, la quarta i darrera té a veure amb la frustració absoluta de la predisposició d'Alfons a concloure una lliga amb el mateix Muhammad VIII, l'estiu de 1429, durant la guerra amb Castella, en contra de Joan II.

\section{a) Joan Mercader i el "contracte de la seda"}

El primer cop de timó fort que Joan Mercader va imprimir en la política granadina d'Alfons el Magnànim està relacionat amb el seu intent d'impedir que un grup de mercaders valencians ${ }^{18}$ aconseguissin tirar endavant la signatura del "contracte de la seda», un acord amb Yusuf III de Granada que els atribuïa el monopoli d'importació de la seda granadina ${ }^{19}$.

18 Lluís i Galceran d'Eixarc, Lluís Granollers, Joan Baiona, Pere d’Àries i Joan Martorell; les dades que he recopilat de cadascun d'ells les he agrupades a R. SALICRÚ I LLUCH, La presència comercial catalanoaragonesa al sultanat de Granada durant el regnat d'Alfons el Magnànim, dins La Corona d'Aragona ai tempi di Alfonso il Magnanimo. XVI Congresso Internazionale di Storia della Corona d'Aragona. Napoli, settembre 1997, en curs de publicació (amb versió en anglès, també en premsa, a The Catalano-Aragonese Commercial Presence in the Sultanate of Granada during the Reign of Alphonso the Magnanimous, "Al-Masaq").

19 «han contractat ab lo rey de Granada de agabellar totes les sedes, ço és, que alguns altres mercaders, christians, moros ne juheus, ne altres, no puxen comprar alguna seda ne roba de seda en lo reyalme de Granada sinó de poder dels dessús dits» (ACA, C., CR Alfons IV, caixa 4, núm. 410. 1417, febrer, 22. València; ed. B. GARÍ, R. SALICRÚ, Las ciudades del triángulo: Granada, Málaga, Almería y el comercio mediterráneo de la Edad Media, dins D. ABULAFIA y B. GARÍ (dir.), En las costas del Mediterráneo Occidental: Las ciudades de la Península lbérica y del reino de Mallorca y el comercio mediterráneo en la Edad Media, Editorial Omega, Barcelona, 1996, doc. 2). Vegeu, sobre el monopoli, R. SALICRÚ, El sultanat..., pp. 136-141; R. ARIÉ, L'Espagne musulmane au temps des Nasrides: 1232-1492. Réimpression suivie d'une postface et d'une mise à jour par l'auteur, París, de Boccard, 1990, p. 362, nota 3, ja n'havia donat notícia, encara que parcialment errònia, a causa de les indicacions confuses que aporta S. CARRERES ZACARÉS, Valencia y Alfonso el Magnánimo, «Anales del Centro de Cultura Valenciana" XIV (1946), pp. 194-195, a partir de la documentació municipal valenciana. El "contracte de la seda» també havia estat esmentat, reiteradament, per diversos historiadors valencians, per bé que creient que hi havia implicats mercaders sarraïns valencians i no 
Segons una carta que Mercader va enviar al Magnànim el 22 de febrer de 1417, aquests mercaders augmentaven lo dret del dit rey de Granada, qui és acostumat ésser deu per çentenar, que sia quinze per çentenar. I com que, segons el batlle, la seda era la base de les importacions valencianes del regne nassarita i nol.s po]t exir esmerç gros de Granada sens la seda, gaudir del monopoli de la seda també suposava, indirectament, gaudir del monopoli de les importacions i exportacions de i a Granada, almenys de les valencianes, de manera que, per aquesta indirectitud, lo rey de Granada collirà lo dit dret de quinze per çentenar no solament de la seda de son regne, ans encara de tots los avers d'aquest regne qui sien per a anar II $\mathrm{a}^{20}$.

Joan Mercader - recollint, probablement, les queixes dels mercaders valencians per l'increment del dret d'un $10 \%$ a un $15 \%$ i amb la clarividència de raonaments que el caracteritzava ${ }^{21}$ - va enviar a Alfons el Magnànim el cadi reial Ali de Bellvís amb la intenció que el monarca, després de sentir els seus arguments, ordenés fer les provisions necessàries per deturar el contracte i enviés Bellvía a Granada per fer desistir el nassarita i els mercaders valencians del seu propòsit.

Alfons, en efecte, es rendí als arguments del jurista valencià. Però aquest fet en si mateix no seria possiblement ni remarcable si no fos perquè, abans de fer-ho, el Magnànim havia donat ordres en un sentit completament contrari i s'havia mostrat entusiasmat amb la idea que uns seus vassalls arribessin a fer tan bons tractes amb el sultà nassarita.

Abans de rebre aquesta carta del batlle de València i que aquest li manifestés que considerava que l'augment del dret de la seda no només repercutia negativament en el braç mercantil del regne de València sinó que també lesionava els drets reials, el rei

pas, com testimonia la carta de Mercader, mercaders christians (vegeu, per exemple, G. NAVARRO ESPINACH, El despegue de la industria sedera en la Valencia del siglo XV, València, Generalitat de València-Consell Valencià de Cultura, 1992, p. 40 i nota 46, que cita R. NARBONA, Gobierno político y luchas sociales. Estrategias de poder del patriciado urbano. La ciudad de Valencia (1356-1419), València, Universitat, 1989, tesi doctoral inèdita; R. NARBONA, Valencia, municipio medieval. Poder político y luchas ciudadanas. 1239-1418, València, Ajuntament de València, 1995, p. 156 i nota 75; P. IRADIEL MURUGARREN, G. NAVARRO ESPINACH, La seda en Valencia en la Edad Media, dins España y Portugal en las rutas de la seda. Diez siglos de producción y comercio entre Oriente y Occidente, Barcelona, Universitat, 1996, p. 186, o M. RUZAFA GARCÍA, Los operadores económicos de la morería de Valencia, dins Actas. IV Simposio Internacional de Mudejarismo: Economía. Teruel, $17-$ 19 septiembre de 1987, Teruel, Instituto de Estudios Turolenses, 1992, p. 252).

20 ACA, C., CR Alfons IV, caixa 4, núm. 410. 1417, febrer, 22. València; ed. B. GARÍ, R. SALICRÚ, Las ciudades..., doc. 2.

21 "de què.s segueix gran dan en aquest regne, axí al braç de la mercaderia com a vostres drets, e encara a t[o]ta la cosa pública d'aquest regne, per ço car, agabellades les dites sedes en Granada que hajen a venir [a] poder dels dits çerts mercaders, se segueix que tots los avers d'aquest [r]egne qui sien d'entrada o d'e[ix]ida per a Granada serien agabellats a aquestes persones matexes, car I[o]s mercaders que acostumen $\mathrm{p}$ [or]tar drapades et altres avers d'aquesta çiutat a Granada, si no po[de]n haver retorn sinó a mà dels dessús dits, no porien sinó perdre e, per consegüent, aquells qui seran senyors de la exida, car no['s p]ot exir esmerç gros de Granada sens la seda, seran senyors de la entrada, e si són senyors de la entra[d]a de Granada seran senyors de la exida d'aquest regne» (ibídem). 
Alfons, potser influït per l'eufòria dels mercaders beneficiaris del contracte, que l'havien anat a trobar a Tortosa abans de partir cap a Granada per signar-lo, els havia recomanat a Yusuf III, tot manifestant-li el seu gran plaer per l'assoliment de l'acord²2.

Però, un cop hagué rebut la carta del batile i escoltat Ali de Bellvís, capgirà completament la seva actitud $i$ intentà, per tots els mitjans, impedir que els mercaders signessin aquell contracte que, aleshores, considerava axi prejudicial a nostres drets $e$ vassalls: manà a Mercader que fes tot allò que estigués a les seves mans per tal d'aconseguir-ho' ${ }^{23}$; escrigué als valencians que n'eren beneficiaris per comunicar-los que revocava la carta de recomanació que havia adreçat, en favor llur, a Yusuf III i que els prohibia que la hi presentessin i que, en virtut d'aquella, fermessin el contracte o fessin cap més pas sense el consentiment i voluntat expressos de Joan Mercader ${ }^{24}$; tornà a escriure al rei de Granada mostrant-li, aquest cop, la seva desagradable sorpresa pel fet que hagués permès que aquells mercaders valencians negociessin aquell contracte sobre la merqua, entrada i sortida de sedes i d'altres mercaderies del sultanat, adduint que els seus antecessors sempre havien deixat que es venguessin sense imposició de gabelles; li pregà que fes revocar un contracte que —ara, a diferència d'allò que havia considerat unes setmanes abans - era tan perjudicial, i tant pels mercaders catalanoaragonesos com pels seus vassalls granadins; i li envià Ali de Bellvís ${ }^{25}$.

Poc després de tot això, el rei degué rebre noves pressions de signe contrari a l'opinió de Mercader $i$, donant mostres de considerables dubitacions, acabà ordenant al batlle de València que, a desgrat de les cartes expedides anteriorment i per algunes raons que no volia exposar-li per escrit, sobresegués qualsevol pas que hagués fet sobre l'anada del cadi a Granada fins que ell arribés a València i pogués examinar personalment el contracte ${ }^{26}$.

Però, un cop rebudes aquestes contraordres, el batlle degué contraatacar perquè, el 26 de març, ja havia aconseguit que el Magnànim hagués tornat a canviar d'opinió.

22 ACA, C., reg. 2561, f. 175r, i reg. 2562, f. 30r-v. 1417, febrer, 8. Tortosa (es tracta de dues versions, l'una en aragonès i l'altra en català, de la mateixa carta); ed. R. SALICRÚ I LLUCH, Relacions de la Corona d'Aragó amb el regne de Granada al segle XV (1412-1458), Barcelona, Universitat, 1997 [edició en microforma], vol. II, doc. 19.

23 "provehiscats per totes aquelles maneres que.us sien possibles que lo dit contracte axí prejudicial a nostres drets e vassalls sia desviat» (ACA, C., reg. 2665, f. 136v. 1417, març, 2. Fuentes; ed. ibídem, doc. 22).

24 ACA, C., reg. 2562, f. 37r-v. 1417, març, 1. Fuentes.

25 ACA, C., reg. 2563, f. 37r. 1417, març, 2. Fuentes. La carta porta implícita una mena d'amenaça a la «plena liberalitat» amb la que els monarques catalanoaragonesos sempre havien respectat, segons sunna e xara, els granadins.

26 "en dies passats vos scrivim manants-vos que fahésseu sobresseure Ali de Bellvís, alcadí nostre en aquex regne, en la anada que fer devia al regne de Granada sobre lo fet del contracte que alguns mercaders de nostra senyoria han menejat e entenen cloure ab lo rey de Granada, car intenció nostra era que, com fóssem presents en aquex regne, veéssem e examinàssem diligentment si lo dit contracte era útil o no a nós e a nostres regnes» (ACA, C., reg. 2410, ff. 149v-150r. 1417, març, 26. Calataiud; ed. R. SALICRÚ, Relacions..., vol. II, doc. 23). 
Aleshores, el rei assegurava que havia sabut que alguns dels mercaders que han menejat e entenen cloure ab lo rey de Granada el contracte, ab poder bastant dels altres, ja havien marxat cap a Granada per a cloure-l'hi, sense esperar la decisió reial, de manera que, si lo dit contracte se fermava, fàcilment no.s poria retractar, per tant, tornà a manar al batlle que fes partir, immediatament, Ali de Bellvís cap al sultanat, $i$ que li donés instruccions ben concretes: primerament, presente les letres per nós fetes e dreçades als dits mercaders per les quals los manam que.s abstinguen de cloure e fermar lo dit contracte, e crehem que axi ho faran; però si s'hi negaven i lo dit alcadí conegua o senta certament que los dits mercaders no vullan desistir de fermar lo dit contracte, llavors hauria de presentar al rei de Granada i a tothom que pogués intercedir en favor de l'aturada del contracte les cartes que Alfons li hauria lliurat, i podria de fer ús de tots aquells remeys que sien convegents a la cosat.

Si bé aquesta és la darrera notícia directa de l'afer que ens aporta la documentació de cancelleria, les fonts municipals valencianes, en canvi, continuen donant mostra de la implicació i interessos del batlle en l'afer, però, segons sembla, un cop el contracte ja havia estat signat: el 31 de juliol de 1417, a València, hom decidia convocar lo honorable batle, qui impugna aquest contracte, juntament amb els mercaders (tant els que tenien part en l'afer com els que no) i els paraires per veure si lo dit contracte és dampnós als dits perayres e cosa pública e, si axí és, facen instància en la revocació de aquell, tant com per justícia fer se puxa ${ }^{28}$.

Per tant, sembla ser que aquesta vegada, encara que Mercader hagués aconseguit convèncer i fer canviar d'actitud i d'opinió el monarca, ja no va poder evitar que el sultà nassarita i els mercaders valencians implicats arribessin a concloure l'acord. Això, tanmateix, no el donà pas per vençut, perquè, com veurem, les innovacions fiscals que havia introduït el contracte, aquesta gran novitat, foren un dels cavalls de batalla que portaren al fracàs de la treva de 1418, una treva que, no pas casualment, fou absolutament negociada i dirigida pel nostre batlle general.

\section{b) El paper de Mercader en la negociació i signatura de la treva de 1418}

No ens pertoca pas, aquí, analitzar el contingut ${ }^{29}$ ni els fets que envoltaren tant la negociació i signatura, primer ${ }^{30}$, com el fracàs i anul.lació, després ${ }^{31}$, del tractat de 1418, sinó només destacar el paper que Joan Mercader va tenir en tot això.

El febrer de 1418, Muhammad VIII el Petit de Granada, fill de Yusuf III, que havia mort el novembre de l'any anterior, va enviar a la Corona d'Aragó un ambaixador, l'alcaid

27 ACA, C., reg. 2410, ff. 149v-150r. 1417, març, 26. Calataiud; ed. R. SALICRÚ, Relacions..., vol. II, doc. 23.

28 Arxiu Municipal de València, Manuals de Consell, A-26, ff. 269v; he pogut localitzar aquest document gràcies a la referència que en dóna G. NAVARRO, El despegue..., p. 40 i nota 46, que cita, a la vegada, com ja he dit més amunt, R. NARBONA, Gobierno político..., p. 812 i nota 121.

29 Sobre el contingut de la treva de 1418, vegeu R. SALICRÚ, La treva...

30 . Vegeu R. SALICRÚ, El sultanat..., pp. 145-155.

31 Ibidem, pp. 155-164. 
nassarita Hayrin, amb la intenció que el catalanoaragonès acceptés de negociar-hi un tractat de pau ${ }^{32}$. A mitjan mes d'abril, el missatger nassarita ja era a punt de tornar cap a les seves terres i el Magnànim ja havia acceptat entaular-hi negociacions, tal com posa de manifest una carta adreçada a Muhammad VIII on li notificava, a més, que havia encarregat al batlle general del regne de València, Joan Mercader, que s'ocupés de tot allò que estigués relacionat amb l'ambaixada $\mathbf{i}$, en conseqüència, que s'ocupés de la negociació del tractat $^{33}$.

Mercader s'ocupà a consciència, i amb tota celeritat, de tot allò que li havia estat comissionat i, ben aviat, ja es féu traslladar i registrar als llibres de l'ofici diversos documents relacionats amb anteriors pactes amb el regne de Granada. A la primeria d'abril, pagà el trasllat de dues paus de Martí amb Granada; a la fi de maig, altres paus e treves fermades per los senyors reys d'Aragó (...) ab los reys de Granada; i, posteriorment, encara una altra pau del rey de Granada fermada ab lo senyor rey en Pere el Cerimoniós ${ }^{34}$.

El batlle féu, per tant, un notable esforç de recerca i de recopilació abans de passar a la redacció del text de la treva, un text que, després de l'etapa ferraniana, durant la qual les treves amb Granada no foren més que treves estrictament castellanes que el monarca catalanoaragonès féu extensives, també, a la Corona d'Aragó, representà la recuperació de la tradició catalanoaragonesa ${ }^{35}$, mèrit que, sens dubte, hem d'atribuir al batlle general del regne de València.

La intervenció de Mercader, però, no acabà pas aquí, ni quedà limitada a la redacció del document; perquè Mercader en preveié, un a un, cadascun dels detalls, i donà instruccions tan minucioses al Magnànim que aquest, pràcticament, ja només hagué de limitar-se a signar l'acord.

Quan l'ambaixador nassarita tornà a València, a mitjan mes de juny, Mercader comunicà a Alfons, que era a Saragossa, que, per tal que el pogués despatxar més ràpidament, ell mateix ja s'havia ocupat d'examinar la procura que duia de Muhammad VIII, i que la considerava suficient. Però, a més a més, gairebé com si hi hagués hagut un canvi de papers, li donà instruccions sobre allò que creia que havia de fer perquè les seguís al peu de la lletra: El batlle ja havia fet redactar el document de la pau d'acord amb allò que havia acordat amb Hayrin, de manera que Alfons només hauria de fer-hi escriure el temps que volia que durés el tractat, però que ell li aconsellava que fos, com a màxim, de dos anys $o$, si no, com a mínim d'un. Un cop Alfons hagués anotat la durada del tracte, ja només caldria que tant ell com el missatger, com a procurador del rei de Granada, el fermessin, cosa que haurien de fer en poder del pronotari o del secretari reial. Després, Alfons hauria de decidir qui volia que anés a Granada tant per ser present a la ratificació de la pau com per complir i fer complir tot allò que

32 ACA, C., Cartes Àrabs, caixa 6, núm. 180.

33 ACA, C., reg. 2664, f. 107v. 1418, abril, 17. València.

34 ARV, MR, Comptes d'Administració, reg. 38 (1418), ff. 158r i 160v.

35 A R. SALICRÚ, La treva..., analitzo, un per un, el contingut dels capítols de la treva i l'origen o presència de cadascun d'aquests en els tractats anteriors. 
s'hi preveia. Per tant, hauria de fer procura suficient per a tot això a la persona designada. Finalment, el batlle posava de manifest que, segons ell, seria convenient que quan el missatger granadí -que era a Saragossa amb el monarca- tornés cap a València, Alfons ja li enviés amb ell tant la persona que hagués elegit per anar a Granada com els seus poders, per tal que ambdós poguessin partir de seguida i enllestirho tot ben ràpidament ${ }^{36}$.

Aquesta carta amb instruccions tan precises de Mercader mostra fins a quin punt Alfons delegà en ell no només la negociació de la treva, sinó també totes les gestions per a la seva conclusió; però, a la vegada, també palesa fins a quin punt el Magnànim va desentendre-se'n, o fins a quin punt, a diferència del seu pare, desconeixia la mecànica d'un pacte semblant.

Només hauria calgut que fos Mercader mateix qui nomenés l'ambaixador catalanoaragonès per poder dir que el batlle es féu, absolutament, càrrec de tot. I, en realitat, poc hi faltà. Perquè encara que no sapiguem qui fou, al capdavall, qui el designà, ni si la seva anada a Granada fou per mèrits propis, en compensació dels serveis prestats pel seu pare o influït per ell, o perquè Alfons cregué que ningú no podia ser tan grat i proper a la voluntat del batlle, i capaç de transmetre-la i d'adequar-s'hi, com el seu propi fill, el fet és que l'ambaixador que partí a Granada amb Hayrin fou, ni més ni menys, que un fill de Joan Mercader, Berenguer, el futur batlle general del regne de València que, aleshores, era cambrer reial ${ }^{37}$. Per tant, Joan Mercader pogué controlar, fins i tot, l'ambaixador i l'ambaixada catalanoaragonesa a Granada.

\section{c) Joan Mercader i el fracàs de la treva de 1418}

Un cop Alfons el Magnànim i l'ambaixador nassarita Hayrin, amb poders del sultà, hagueren signat, el 4 i 5 de juliol de 1418, respectivament ${ }^{38}$, la treva -que, tal com volia el batlle, era de dos anys-, Hayrin i Berenguer Mercader partiren, segurament junts cap a Granada ${ }^{39}$, on, un cop arribats, Muhammad VIII tindria quinze dies per ratificar el tractat.

Resultà, però, que, segons el sultà nassarita i el seu algutzir major, l'alcaid Yamin, el text que Berenguer Mercader duia per ratificar no es corresponia amb el que Hayrin hauria hagut d'acordar, i que el que Hayrin i Berenguer asseguraven que l'ambaixador

36 ACA, C., CR Alfons IV, caixa 7, núm. 867. 1418, juny, 17. València; ed. R. SALICRÚ, Relacions..., doc. 44.

37 Que ja fou recomanat a Muhammad el Petit, des de Saragossa, el 7 de juliol (ACA, C., reg. 2666, ff. 3v-4r. 1418, juliol, 7. Saragossa; ed. A. GIMÉNEZ SOLER, La Corona de Aragón y Granada, «BRABLB» IV (1907-1908), p. 369).

38 ACA, C., reg. 2641, ff. 153v-156r. 1418, juliol, 4. Saragossa; ed. R. SALICRÚ, Relacions..., vol. II, doc. 45.

39 El granadí deixà València el 7 d'agost (cf. ARV, MR, Comptes d'Administració, reg. 38 (1418), f. 139r) i, probablement, ja ho féu acompanyat de Berenguer, a qui, pocs dies abans, el 25 de juliol, amb ordres adreçades al seu pare, Alfons ja havia ordenat que li fos bestret tot allò que necessités per realitzar el viatge (cf. ACA, C., reg. 2666, f. 12v. 1418, juliol, 25. Saragossa). 
nassarita havia acceptat i signat a Saragossa tampoc no concordava. En conseqüència, després de diverses temptatives dels nassarites per arribar a un nou acord i perquè no es trenguessin les negociacions, Berenguer Mercader no pogué fer altra cosa que deixar transcórrer, a Granada, els quinze dies preceptius i emprendre, tot seguit, el camí de retorn cap a terres cristianes ${ }^{40}$.

Per bé que no puguem treure l'entrellat del que realment succeí amb Hayrin i amb els seus poders, ni saber per quin motiu resultà, després de tantes precaucions com havia tingut el batlle en examinar les seves credencials, que el text que el nassarita signà a Saragossa després no fou considerat vàlid un cop a l'Alhambra, el que sí que és evident és que, rere el fracàs de la treva, hi podem situar, encara que sigui indirectament, Joan Mercader mateix, o si més no les exigències i pretensions del batlle que havia elaborat, tan a consciència, el tractat. Perquè, en la carta que Berenguer Mercader trameté a Alfons el Magnànim per explicar-li tot el que havia passat, escrita a Alcalá la Real el 4 de setembre de $1418^{41}$, queda de manifest que un dels capítols que més molestaven als granadins, i que no volien acceptar, però que Berenguer Mercader, influït indubtablement pel seu pare, es negava a consultar a Alfons, era justament el que feia referència al dret de la seda que es estat imposat novament als mercades catalanoaragonesos, és a dir, a l'augment del 10\% fins al $15 \%$ del dret que s'havia produït arran de la signatura del "contracte de la seda». I és evident que, aquí darrere, hi havia, per força, la mà del batlle, del mateix Joan Mercader que havia intentat evitar la signatura del contracte, que n'havia convençut Alfons i que, com que havia fet tard i no s'havia sortit amb la seva, ara, de nou, a través del tractat, tornava a intentar que es neutralitzessin, com fos, els efectes nocius d'aquest monopoli.

Cal advertir, tanmateix, que al text de la treva l'increment del dret de la seda no apareix pas esmentat de manera explícita, com ho fa a la carta de Berenguer Mercader, sinó que queda camuflat rere un capítol més general que preveu, només, que los ditos vassallos de cadauno de nós, ditos reyes, no sean tenidos pagar dreytos algunos que sean puestos aprés del tiempo de la paz que fue contractada entre los reyes don Martín (...) e don Mahomat. perquè, en el fons, aquesta clàusula no és més que el reflex de la particular concepció que Joan Mercader tenia del dret de la seda, com a imposició que afectava globalment, encara que de manera indirecta, tot el comerç amb Granada. I, en contrapartida, això també permet entendre perquè, en canvi, a diferència del text de la treva, la carta de Berenguer Mercader polaritza la pugna fiscal en el dret de la seda: perquè, en aquest punt, la carta de l'ambaixador parla per boca

40 Vegeu a A. GIMÉNEZ, La Corona..., «BRABLB» IV (1907-1908), pp. 370-372, el relat que Berenguer Mercader mateix presentà dels fets a Alfons el Magnànim, segons una carta escrita el 4 de setembre de 1418 des d'Alcalá la Real que, actualment, es dóna per perduda. Per a la versió granadina dels fets, remeto a les cartes de Muhammad VIII i de l'alcaid Yamin (ACA, C., Cartes Àrabs, caixa 6, núm. 108. [1418], setembre, 4. Granada, ed. ibídem, pp. 369-370 i R. SALICRÜ, Relacions..., vol. II, doc. 47; i ACA, C., CR Alfons IV, caixa 21, núm. 114. [1418], setembre, 4. S.I. [Granada], ed. ibídem, doc. 46).

41 Vegeu la nota anterior. 
dels nassarites, que sabien perfectament què volia amagar, en realitat, aquest capítol abstracte.

\section{d) Joan Mercader i l'intent del Magnànim de fer Iliga amb Muhammad VIII el Petit durant la guerra amb Castella (1429)}

El quart i darrer testimoniatge significatiu de la influència que Joan Mercader, batlle general del regne de València, exercí en la política granadina d'Alfons el Magnànim el trobem l'estiu de 1429, després que s'hagués iniciat, obertament, la guerra catalanoaragonesa amb Castella.

Encara que, des del novembre de 1428, tant Joan II de Castella com Alfons el Magnànim haguessin iniciat contactes $\mathrm{i}$ donat suport als partidaris de Muhammad IX l'Esquerrà, que el 1427 havia estat destronat per Muhammad VIII el Petit i s'havia refugiat a Tunis ${ }^{42}$, i encara que Joan II hauria volgut, probablement, reprendre les hostilitats amb Granada aprofitant l'expiració, el 26 de febrer de $1429^{43}$, d'una treva amb Muhammad VIII, l'eventualitat que va suposar l'esclat de la guerra amb la Corona d'Aragó ${ }^{44}$ degué fer-li intentar recuperar (amb el mateix raonament que després impulsà Alfons el Magnànìm: “o ell, o jo») l'aliança amb Muhammad VIII el Petit per evitar que, altrament, fos la Corona d'Aragó qui se'n beneficiés.

Aquests rumors arribaren, ben aviat, a la darreria de juliol, a orelles d'Alfons el Magnànim i, precisament, a través d'una carta del batlle del regne de València, Joan Mercader, que li lliurà el seu fill Berenguer.

Segons Joan Mercader, semblava que el rei de Castella havia mogut tracte amb el rei de Granada i que li havia proposat i demanat lliga i ajut de gent d'armes en contra d'Alfons. De moment, segons el batlle, la cosa no era pas, encara, en térmens certes,

42 Vegeu-ho a R. SALICRÚ I LLUCH, La Corona de Aragón y los nazaritas en el segundo reinado de Muhammad el Pequeño (1427-1429), dins La frontera oriental nazarí como sujeto histórico (s. XIII-XVI). Actas del Congreso, Almeria, Instituto de Estudios Almerienses, 1997, pp. 199-211.

43 Cf. J. ABELLÁN PÉREZ (ed.), Documentos de Juan //, Múrcia-Cadis, Academia Alfonso X El Sabio - Servicio de Publicaciones de la Universidad de Cádiz-- CSIC (Colección de Documentos para la Historia del Reino de Murcia XVI), 1984, pp. 381-382.

44 Les cròniques segueixen essent, per ara, la millor font per conèixer el desenvolupament i evolució de la guerra entre Castella i la Corona d'Aragó de 1429-1430. Vegeu, tanmateix, A. RYDER, Alfonso el Magnánimo, rey de Aragón, Nápoles y Sicilia (1396-1458), València, Edicions Altons el Magnànim, 1992, pp. 197 i següents, o J. VICENS I VIVES, Juan II de Aragón (1398-1479). Monarquía y revolución en la España del siglo XV, Barcelona, Editorial Teide, 1953, pp. 56-65; per a una visió més sumària, idem, Els Trastàmares (segle XV), Barcelona, Editorial Vicens-Vives, 1969 (2a. reimpressió), pp. 120122, i vegeu també M. GUAL CAMARENA, Las treguas de Majano entre Aragón, Navarra y Castilla (1430), "Cuadernos de Historia de España» XVI (1951), pp. 79-109; pel que fa a aspectes més concrets de la guerra, J. HINOJOSA MONTALVO, Las fronteras valencianas durante la Guerra con Castilla (14291430), «Saitabi», 37 (1987), pp. 149-157; J. ABELLÁN PÉREZ, Participación de la ciudad de Murcia en la guerra civil castellana (1429-1430), “CEM» IV-V (1976-1977 [1979]), pp. 9-25; A. DÍAZ BORRÁS, Alzira, una población de retaguardia en la guerra con Castilla (1429-1430), "Al-Gezira» 3 (octubre 1987), pp. 93-113. 
perquè els rumors no s'havien pogut verificar. Però, tot i amb això, i considerant la mala intenció que, segons ell, tenia el rei de Castella, el Magnànim temia que, si no hi intervenia, el tracte aniria endavant i s'arribaria a concloure.

Per aquest motiu, el dia 2 d'agost, Alfons respongué a Mercader que considerava molt necessari enviar un missatger a Granada, i que volia que parlés immediatament amb Joan Martorell (un dels beneficiaris del contracte de la seda, mercader valencià que comerciava assíduament amb Granada i que, almenys el 1420, estava establert a Màlaga ${ }^{45}$ ) per convèncer-lo que fos ell mateix qui hi anés tot seguit - cosa que significa, òbviament, que aleshores era a València-; i que en cas que, per alguna causa raonable, no pogués anar-hi, ell mateix, el batlle, s'encarregués de trobar una altra persona idònia, de parlar amb ella i de fer que partís sense dilació.

Alfons volia que el missatger catalanoaragonès que anés a Granada rebés, de part seva però per boca de Mercader, instruccions ben clares. En primer lloc, hauria d'intentar que Muhammad VIII accedís i es comprometés a mantenir-se neutral en la guerra entre Castella i la Corona d'Aragó. Però, si no podia aconseguir-ho de cap manera, hauria d'intentar obtenir-hi ell mateix, com fos, lliga en contra de Castella. Alfons assegurava que, com que havia estat el monarca castellà el primer a intentar promoure el tracte, ell mateix també se sentia legitimat per pactar-hi lícitament, sobretot si no podia obtenir garanties de la seva neutralitat. I, per tant, volia que, tan bon punt el batlle hagués parlat amb Martorell i hagués pogut decidir qui marxava cap a Granada, li ho notifiqués tot seguit, per tal que li pogués enviar, immediatament, les credencials del missatger i aquest pogués partir sense entretenir-se ni perdre temps per res ${ }^{46}$.

No hi ha pas dubte, per tant, que, d'entrada, encara que fos encobrint les possibles reticències amb justificacions que culpabilitzaven el rei de Castella de la pròpia actitud, Alfons estava ben decidit a tirar endavant la lliga amb Granada.

Però, tot $i$ amb això, no trigà gaire a canviar, de nou, completament de parer, donant noves mostres d'una considerable manca de criteri i evidenciant, un cop més, fins a quin punt valorava els consells del batlle general del regne de València o bé, si es vol, fins a quin punt es deixava influir, sense límits, per ell.

Perquè a Alfons només li calgué que Mercader li exposés, per carta, què pensava d'aquests afers del regne de Granada, per arribar a assegurar, tan sols deu dies després, el 12 d'agost, que donava per bona l'opinió del batlle i que, d'acord amb ella, no tenia pas cap intenció d'ofendre Déu fent lliga amb un rei infidel en contra d'un rei cristià; i per mostrar-se convençut, també, sense ni la més petita ombra de dubte, que si el seu adversari, el rei de Castella, tenia la gosadia o cometia l'aberració de fer lliga o concòrdia amb el rei de Granada, infidel, en contra seva, Déu el confondria i ell obtindria la victòria ${ }^{47}$.

45 Vegeu, sobre aquest Joan Martorell que no tenia parentiu directe amb l'homònim autor del Tirant, les dades que n'he pogut recollir a R. SALICRÚ, La presència... (o bé a idem, The CatalanoAragonese...).

46 ACA, C., reg. 2677, ff. 114v-115r. 1429, agost, 2. Calataiud; ed. R. SALICRÚ, Relacions..., vol. II, doc. 120.

47 ACA, C., reg. 2579, t. 109v. 1429, agost, 12. Calataiud. 
I és que si bé hom acceptava, fàcilment, la licitud d'una treva, d'una suspensió d'hostilitats, d'un pacte d'amistat 0 , fins i tot, com féu reiteradament el mateix Joan de Castella, d'una aliança amb un infidel — candidat al tron nassarita - per combatre'n un altre, una lliga destinada a danyar un coreligionari per mitjà d'una aliança contra natura amb un enemic de la fe catòlica era tota una altra cosa, plenament condemnable. La reprobabilitat d'aquesta mena d'aliances amb l'objectiu d'escometre un altre monarca cristià havia quedat palesa, uns anys abans, durant l'Interregne, quan foren interceptades les cartes i ambaixada que Jaume d'Urgell enviava a Yusuf III de Granada amb la intenció d'aliar-s'hi contra l'infant Ferran de Castella ${ }^{48}$. Però, evidentment, tot depenia d'allò que es considerés que hi havia en joc, i hom sempre podia superar, si així ho volia, els esculls i escrúpols de la consciència.

Aquesta vegada, el major rigor de Mercader l'havia acabat frenant, però Alfons havia trobat la seva coartada moral en el fet que la iniciativa havia estat, en primera instància, de Joan II de Castella, cosa que l'hauria pogut legitimar a fer ús de les mateixes armes.

Tanmateix (però ara sense que es posessin de manifest les reticències del batlle $i$, potser per això, convertint la proposta en realitat), la tardor de l'any següent $i$ amb Muhammad IX — que s'oposava a la vegada a Castella i al seu rival Muhammad VIII ${ }^{49}$ com a aliat, el Magnànim tornà a preveure una possibilitat semblant. Però, tot i així, per descarregar-se la consciència, esperava que fos Muhammad IX qui li proposés una treva i, si volia anar més enllà, li pogués plantejar lliga. L'ambaixador a Granada, que era, altra vegada, Berenguer Mercader, hauria de fer tot el que fos per tal que la proposta fos del nassarita. I, fins i tot així, hauria de consultar-la i plantejar-la a Alfons per cifra, és a dir, amb correu xifrat, per evitar que, si les cartes eren interceptades, el rei de Castella pogués descobrir de què anaven els tractes i pogués denunciar un fet $\tan$ execrable ${ }^{50}$.

L'octubre de 1430 la iniciativa catalanoaragonesa tampoc no arribà a bon port, perquè abans que pogués concretar-se Muhammad IX ja fou capaç de sortir-se'n amb els seus propis mitjans i sense necessitat d'obtenir o de demanar ajut cristià. Però, com demostra el fet que fos Berenguer Mercader qui havia d'encapçalar l'ambaixada, és evident que, aleshores, la temptativa devia comptar amb el beneplàcit del batlle general; altrament, Alfons difícilment hauria gosat aventurar-s'hi, perquè, com seguí demostrant-li, com fins ara, al llarg del seu regnat, aquest batlle era, respecte a Granada, el seu principal conseller i aliat.

Alfons difícilment hauria pogut contradir Mercader; però encara més difícilment s'hauria deixat contradir la clarividència, perspicàcia i lucidesa d'un estadista de la talla de Joan Mercader.

48 Vegeu-ho, més per extens, a R. SALICRÚ, El sultanat..., pp. 48-63.

49 Vegeu-ho ibidem, pp. 269 i següents.

50 Per al memorial d'aquesta ambaixada, ACA, C., reg. 2692, ff. 110v-111r. 1430, octubre, 15. València; ed. R. SALICRÚ, Relacions..., vol. II, doc. 137. 